\title{
Models for Evaluating Tourism Websites
}

\author{
Brito José Bonjisse and Elisabete Paulo Morais \\ Tourism Marketing, Polytechnic Institute of Bragança, Mirandela, Portugal \\ Applied Management Research Unit (UNIAG), Polytechnic Institute of Bragança, Mirandela, \\ Portugal
}

Correspondence should be addressed to: Elisabete Paulo Morais; beta@ipb.pt

Received date: 31 March 2017; Accepted date: 30 June 2017; Published date: 13 October 2017

Academic Editor: Rosalina Bessa Babo

Copyright (C) 2017. Brito José Bonjisse and Elisabete Paulo Morais . Distributed under Creative Commons CC-BY 4.0

\begin{abstract}
This paper reviews tourism studies that pertain to methodological approaches to website evaluation of tourism websites, in order to make future judgement analysis of tourism websites. Although, it is difficult to make a systematic and complete evaluation on websites, they are quality due to their diversity of functionalities, which make them complex to analyses. Many studies have proposed new website evaluation frameworks and criteria. The research attempted to understand and improve website evaluation based on models related to the tourism websites. Through those models, the research proposed a new model based on the previous models discussed on this paper.The method used in the research was qualitative approach like reading journals, books, papers, interpreing phenomena and virtual research by Internet, and according to the findings this analysis found that websites should look on the ergonomics recommendations.
\end{abstract}

Keywords: Tourism, website evaluation, techniques of evaluation

\section{Introduction}

The World Wide Web (WWW) has become the primary instrument used by tourists in order to search for information. As a result, tourism websites pertaining to destinations need to be appealing and must convey their brand image in an appropriate, effective manner.
Destination Marketing Organizations (DMOs) are non-profit institutions (usually public or/ private organizations) responsible for attracting tourists and helping to commercialise hospitality and travel services based in a territory conceived as a single unit, weather a city, a region or a whole nation. (Gretzel, 2006).

Moreover, these institutions are also responsible for the promotion of destination brands. (Blain, 2005). Therefore, several researchers have

Cite this Article as: Brito José Bonjisse and Elisabete Paulo Morais (2017)," Models for Evaluating Tourism Websites", Journal of Internet and e-Business Studies, Vol. 2017 (2017), Article ID 217014, DOI: $10.5171 / 2017.217014$ 
highlighted official websites are crucial like Choi (2007) and Jang (2012) according to them destination websites are important to promote a territory / goods / services because they provide a huge amount of information, convey an image of the place, permit useful interaction with consumers. So the aim of this paper is to identify the evaluation techniques of tourism websites in order to make future judgement analysis of websites.

First, we are going to define tourism, talk about WWW and its importance, followed by models of tourism website evaluation and conclusion.

\section{Literature Review}

The United Nations (UN) and the World Tourism Organization Unwto (2010), specializing in the UN agency for tourism, based in Spain, defines "tourism as a set of activities of persons traveling and staying in places outside their normal environment not more than a year for leisure, business and other reasons not related to paid activities in the place visited." Tourism, according to Unwto (2015), "is the activity traveler visiting a location outside of your usual environment, for less than a year, and with the main purpose different from the exercise of remunerated activities by local entities visited".

The definition of tourism, despite several discussions and contributions in an attempt to define it that prevails is the one of UNWTO, as the World Tourism Organization. It is important to note that the definitions formulated in the UNWTO are related to international tourism statistics and leave blank the other factors linked to the tourism sector and that, there may be more studies on the generally accepted concept.

\section{Internet Marketing of Tourism}

Electronic commerce has a far-reaching impact on the tourism marketPalmer \& McCole (2000).The Internet (with the newest web technology) offers a large amount of information instantly, so it is becoming increasingly important as a destination marketing and promotion tool for the tourism industry (especially for hotels and travel agencies) Brey, So, Kim, \& Morrison (2007) and for large organizations (eg. DMOs), and national tourist organizations (NTOs) Doolin, Burgess, \& Cooper (2002).

Moreover, the web has great potential for promoting regional tourism, and is relatively inexpensive compared with other promotion and advertising media. (Standing \&Vasudavan, 2000). An effective website can reach global audiences: it is accessible $24 \mathrm{~h}$ a day from anywhere in the world. The content of a website is thus very important, and must be updated regularly in the field of tourism marketing as in any other field. (Huang, Chou, \& Lin, 2010).

Travelers search for information on tourism websites and the content of these websites is one of the main factors contributing to repeated visits. (Ho \& Lee, 2007).

Moreover, moving from simply offering information to interactive designs allows tourism organizations to identify consumers' interests and encourage their participation, thereby increasing the likelihood that they will return to the site. This also allows these organizations to understand tourists' preferences and consequently to communicate with them individually and provide them with personalised services. (Doolin et al., 2002). Therefore, many online visitors may be attracted through the use of government tourism websites.

The link between tourism and WWW is so closer today, which means that tourists are seeking products and services through the Internet.

It is important to highlight that there is too much information in the world, but the Internet tools help consumers to get their needs and wants by distance from any destination based on interactivity state websites or destination websites.

Cooper et al. (2002) say the Internet can also strengthen marketing functions and distant destinations communications, 
whether peripheral or by tourism enterprises of small and medium businesses by enabling direct communication with potential consumers. Therefore, it offers unprecedented opportunities and affordable for the representation and global marketing for large and small tourism service providers.

Electronic commerce has a far-reaching impact on the tourism market according to Palmer \& McCole (2000). The Internet (with the newest web technology) offers a large amount of information instantly, so it is becoming increasingly important as a destination marketing and promotion tool for the tourism industry (especially for hotels and travel agencies) (Brey, So, Kim, \& Morrison, 2007; Choi, Lehto, \& Morrison, 2007; Ho, 2002; Kim, Kim, \& Han, 2007) and for large organizations (eg. DMOs, and national tourist organizations (NTOs) (Doolin, Burgess, \& Cooper, 2002; Hoffman \& Novak, 1996; Lee, Cai, \& O’Leary, 2006; Raventos, 2006). Moreover, the web hás great potential for promoting regional tourism, and is relatively inexpensive compared with other promotion and advertising media (Standing \&Vasudavan, 2000). An effective website can reach global audiences: it is accessible $24 \mathrm{~h}$ a day from anywhere in the world. The content of a website is thus very important, and must be updated regularly in the field of tourism marketing as in any other field (Lin \& Huang, 2006).

Travelers search for information on tourism websites, according to Ho \& Liu (2007), and the content of these websites is one of the main factors contributing to repeated visits (Purinton \& Rosen, 2004). Moreover, moving from simply offering information to interactive designs allows tourism organizations to identify consumers' interests and encourage their participation, thereby increasing the likelihood that they will return to the site. This also allows these organizations to understand tourists' preferences and consequently to communicate with them individually and provide them with personalised services Doolin et al. (2002).

The way a website presents information, graphics, and photos in many ways influences how these messages are received by "viewers" Rosen \&Purinton (2004). Therefore, many online visitors may be attracted through the use of government tourism websites.

In the travel agencies market today, there are many alternatives of online agencies that develop interfaces appropriate consumers. The Internet also offers unique opportunity for multimedia presentations, which enables greater interaction of those seeking information and thoese providint it.

However, for tourism to exploit the full potential element of e-commerce and their customers it is necessary to have security in transmissions, guaranteed credibility and accountability of information, ensure copyright, reduce confusion and dissatisfaction of users.With the growth and sophistication of tourist demand, came new dependence of electronic media by consumers, suppliers and intermediaries daily. Increasing numbers of consumers use commercial sites and non-commercial Internet for planning, search, booking, acquisition and changes in tourism products.

Tourist experiences are empowered with information technology and the use of systems of information and booking to improve personal efficiency.

The pages on a site are organized from a basic URL or site where the main page, usually resides in the same directory on a server.

The pages are organized within the site in an observable hierarchy in the URL, although the links between them control how the reader perceives the global structure, so that it can have little to do with the hierarchical structure of the site's files.

\section{The Role and Importance of the Websites}

According to the thesis of Azevedo (2009), websites are increasingly important tools in any marketing strategy. The paradigm shift in business development is leading the 
companies to the growing adoption of a relational model and direct communication with the consumer, as opposed to the traditional model in their marketing strategies. It is in this context that highlights the importance of communication tools, andparticularly the Internet, especially when enriched by appropriate and attuned multimedia content with the marketing plan.

The use of websites and multimedia as tools to support sales, promotion of the image and growth, enhances the performance and profitability of companies.

For all this, they gain increasing importance for the production and content structuring services normally directed to three areas:

Institutional Strand (websites with institutional content) - presentation company their products and or services.

Shed commercial (commercial websites) - Commercial Performance, by providing consumers with direct sales of its products or services. In addition to this commercial aspect, this type of content can also include an institutional component.

\section{Communication support strand (content} in "micro sites") - small set of supporting communication content. Used for special campaigns are generally characterized by a short period of life. A few years ago the navigation tools were more complicated to use, production websites and their content did not have as many tools as today and access was so expensive that only large companies and universities considered the use of the Internet as having a cost / benefit advantage. Today, access is easier and cheaper, site production costs decreased significantly and the associated tools are more accessible. Consequently, the number of Internet users continues to grow.

\section{Websites for Tourism Promotion and Advertising}

The definition of the term website is sometimes ambiguous and -from the point of view of users- it is used as a synonym of web page due to their close relation. Garcia $(2001,6)$ defines a website as a group of pages on the World Wide Web that are regarded as a single entity and are structured according to a rigorous content organisation system. Websites must be accessible and intuitive to allow easy navigation and the customisation of criteria and requirements.

However, today the technological tools are not the only important aspects in the development of a website. As mentioned byGarcia $(2001,6)$ : "the best proposal of any website to make users loyal is to offer quality content... that distinguishes it from other websites. This produces in users the need to return to the website on a regular basis. Differentiating content clearly offers a range of mechanisms (forums, announcements board, chat, email, etc.) to establish a relationship with users".

Lopez, Valarez, \& Altamirano (2016) summarise the essential features of the websites of cities and destinations:

\section{Easy to find, either through a search engine or directly.}

2. Speed. The website must operate and respond quickly.

3. Usability. The site must be attractive, easy to use, graphically coherent, and keep the interest of the

user.

4. Content. The site must provide quality information that is interesting, correct, updated, Creative and entertaining for the user.

5. Interactivity. The website must provide users with the ability to find the information they require, facilitate bookings, links, customer support and service.

All these aspects should be considered when creating a tourism promotion website, since these aspects are becoming increasingly important in the field of communication. "The development of new technologies has led to the perception of 
corporate websites as business cards which communicate by themselves and as powerful tools for access to and for users, so it is convenient and indispensable for the image, information and activities of companies and public bodies to be reflected in their websites. The website is, in short, a communication tool that must be consistent with the institutional objectives, and must contribute to the transmission of information" (Poyatos, Martínez, \& Martínez, 2011).

Promotion through websites needs to be complemented with the creation of profiles on the main social networks, to promote interactive communication in which users can become voluntary content generators and promoters of the tourist destinations.

Websites should promote collaborative tourism communication 2.0 through the generation of quality multimedia content that can be shared and turned viral by tourists 2.0, and through the integration of digital tools that improve the experience of planning and travelling, such as search engines for tourist services, interactive maps, audio guides, traveller applications, etc. They should also include online spaces for advice and communication and collaborative digital platforms in which travellers can share information, references and experiences.

\section{Evaluation and Analysis of Websites}

In the field of communication, it is increasingly important and necessary to monitor and evaluate the implemented communication strategies. However, in the field of digital tourist communication there are no established models or parameters to evaluate the communication strategies carried out through websites.

There are numerous reports from the field of technology that allow improving the construction of websites and models that analyse specific cases based on technical functions. There are also measurement systems that allow the evaluation of the return on investment (ROI) and the impact of advertising. There is an increasing number of tools to measure the results of digital communication campaigns. Under the umbrella term "web analytics", a variety of tools have been developed to measure and analyse data about the behaviour of the online audience and achieve web traffic optimisation and meet the objectives of e-commerce (Lamas, 2010).

However, "it is necessary to work on the development of a method to evaluate the quality andcommunicative efficacy of tourism websites (FernándezCavia, et al., 2010; Fernández Poyatos, Aguirregoitia Martínez \& Boix Martínez, 2011), since search engine optimization (SEO) is currently the main metrics system for websites. In the context of the World Wide Web, SEO is the process of affecting the visibility of a website in search engine results so that it appears among the first results. Likewise, SEO can be defined as the set of procedures and techniques that are intended to provide a website or a web page with maximum visibility on the Internet (Codina \& Marcos, 2005).

\section{Methodology}

This study will be conducted by documental research like reading journals, books, articles, interpreting phenomena and virtual research by Internet. It is important to highlight that this is a qualitative method approach, wich comes to study things in their natural settings about models of tourism evaluation websites found on previous studies, and at the end suggest a new model to following in tourism marketing.

\section{Techniques/Parameters to Evaluate Tourism Website}

The study of parameters to evaluate a website began years ago, but for this chapter appeal models related to tourism website. The main objective is to come up with a presentation of authors' studies, the relationship from them, and then a new proposal to evaluate a website based on those past studies in order to take advantage from new criteria to evaluate a tourism website worldwide. 


\section{Model 1- Standardization of the language according to the parameters, number of indicators and description}

Despite the study done, it is necessary to look on it well, and each author has their point of view when they determine the techniques to evaluate a tourism website. Cavia et al., (2014) mainly focus on the use of a very simple statistical operator: weighted average and also the indicators were evaluated using different measurement scales, depending on their meaning.

The Web Quality Index (WQI) for destination websites is an assessment system that consists of a set of twelve parameters (Table 1) that are examined in each website with the aim of analysing its quality. Each parameter is evaluated by means of a set of indicators that can vary from the presence/absence of an element/feature to a qualitative scale assessed by an expert. The WQI assessment system was built after studying the current website evaluation systems (Cavia et al, 2014).

Table 1 presents the model presented by Cavia et al (2014). In this table, we can observe the parameters evaluated, the number of indicators for each parameter and their description.

Table 1: Model presented by Cavia et al (2014)

\begin{tabular}{|c|c|c|}
\hline Parameters & $\begin{array}{l}\text { Number } \\
\text { of } \\
\text { Indicator } \\
\mathrm{S}\end{array}$ & Description \\
\hline 1.Homepage & 13 & $\begin{array}{l}\text { Measures the suitability and appeal of the websites } \\
\text { homepage }\end{array}$ \\
\hline $\begin{array}{l}\text { 2.Content amount } \\
\text { and quality }\end{array}$ & 15 & $\begin{array}{l}\text { The websites content is assessed in terms of variety and } \\
\text { suitability to the tourists need }\end{array}$ \\
\hline $\begin{array}{l}\text { 3.Information } \\
\text { architecture }\end{array}$ & 10 & $\begin{array}{l}\text { Examines the manner in which the website is organised } \\
\text { and structured in order to enable users to have access to } \\
\text { information }\end{array}$ \\
\hline $\begin{array}{l}\text { 4.Usability and } \\
\text { accessibility }\end{array}$ & 17 & $\begin{array}{l}\text { Looks into user friendliness on the website and availability } \\
\text { for use by people with sensory difficulties }\end{array}$ \\
\hline 5.Positioning & 8 & $\begin{array}{l}\text { Verifies wether the website is designed to assist } \\
\text { positioning algorithms within web search engines }\end{array}$ \\
\hline $\begin{array}{l}\text { 6.Commercializatio } \\
\mathrm{n}\end{array}$ & 7 & $\begin{array}{l}\text { Looks into the options for distributing tourist products and } \\
\text { services through the website }\end{array}$ \\
\hline 7.Languages & 6 & $\begin{array}{l}\text { Assesses the existence of several languages aside from the } \\
\text { official languages of the destination in question }\end{array}$ \\
\hline 8.Brand Image & 12 & $\begin{array}{l}\text { Examines how the destinations brand image is conveyed } \\
\text { and managed via the websites content }\end{array}$ \\
\hline 9.Persuasiveness & 8 & $\begin{array}{l}\text { looks into the websites persuasiveness capacity that is, its } \\
\text { capability to convince visitors that the destination is worth }\end{array}$ \\
\hline
\end{tabular}




\begin{tabular}{|l|l|l|}
\hline 10.Interactivity & 9 & $\begin{array}{l}\text { Examines the two-way communicative relationship } \\
\text { between the user and the website content, between the } \\
\text { user and the destinations managers and between the user } \\
\text { and other users }\end{array}$ \\
\hline 11.Social Web & 13 & $\begin{array}{l}\text { Studies the presence of 2.0 tools on the official destination } \\
\text { website }\end{array}$ \\
\hline $\begin{array}{l}\text { 12.Mobile } \\
\text { communications }\end{array}$ & 5 & $\begin{array}{l}\text { Considers whether the official destination website is } \\
\text { adapted for mobile communication using smartphones or } \\
\text { tablets }\end{array}$ \\
\hline Total & 123 & \\
\hline
\end{tabular}

Source: Adapted from Cavia et al (2014)

\section{Model 2-Computers in Human Behavior}

This study refers to Kim (2006), Fig 1, for the classification of online tourism information sources, so he concluded that there are some elements specifically person blogs, public websites, companies websites, websites for social media. According to his study, it is possible to find out that person blogs is related to travel experience by individual tourist on publishing. Public Website - means that the country of a country that assume the control of marketing destination. Companies' websites-the products or services are provided by tourism companies such as airport, airlines, biodiversity, tourism products and services, etc. Websites for social media related to facebook, whatsapp, twitter, imo, skype and others, where the exchange of tourism information takes place about a trip without limitations in terms of time and space.

This study refers to Loiacono \& Chen (2002), Morrison \& Mill (2003),Schaupp \& Belanger (2005), Lee (2010) for the attributes of websites, and they found that security is defined as the safety of personal information during transactions on a travelwebsite. In general, security as attribute of website should be seen as three ways such as protecting information during transmission and subsequent storage, security for online purchases/reservations, and privacy/confidentiality statements. Also security would be used in many áreas like financial sector, public institutions, and commercial market, at once the users tend to misuse personal information details such as credit card numbers. InteractionMills and Morrison (2003) also defined interactivity as the speed of a travel website, as felt by the user. In this study, interactivity was included as a part of the travel website interface, while Lee (2010) defined interaction for blogs as a quick response between the users and the administrators. Well after their point of studies, it is important to enhance that the interaction is all about the consumers and the tourism information on website. Information-trust-information quality is the ability of the system to convey the intended meaning of information (Chuang \& Yuanzhuo, 2012). Informational fit to task was utilized as information quality was defined as the degree to which the information offered on the website satisfies job requirements and achieves an improvement of performance (Loiacono et al., 2002).

Lee (2005) defined trust as a customer perception of the level of trust mechanisms provided by an online store, while Belanger, Hiller, and Smith (2002) defined trustworthiness as a perception of confidence in the e-marketer's reliability and integrity.

For this study, it is realized that the information-trust due to the characteristics of tourism products and services, such as intangibility, information is crucial, and also tourism needs to look on satisfying the 
needs and wants of consumers. Personalization- has been used in a variety of ways, including tailored communication (Loiacono et al. 2002), and reliability and validity. According to the author, it is possible to note that the online tourism information rose up into 4 types: company websites, and social media websites, blogs, public websites and other attributes were proposed by appealing atention on previous studies on the website evaluation factor, e-commerce success factor, web satisfaction, and so on.

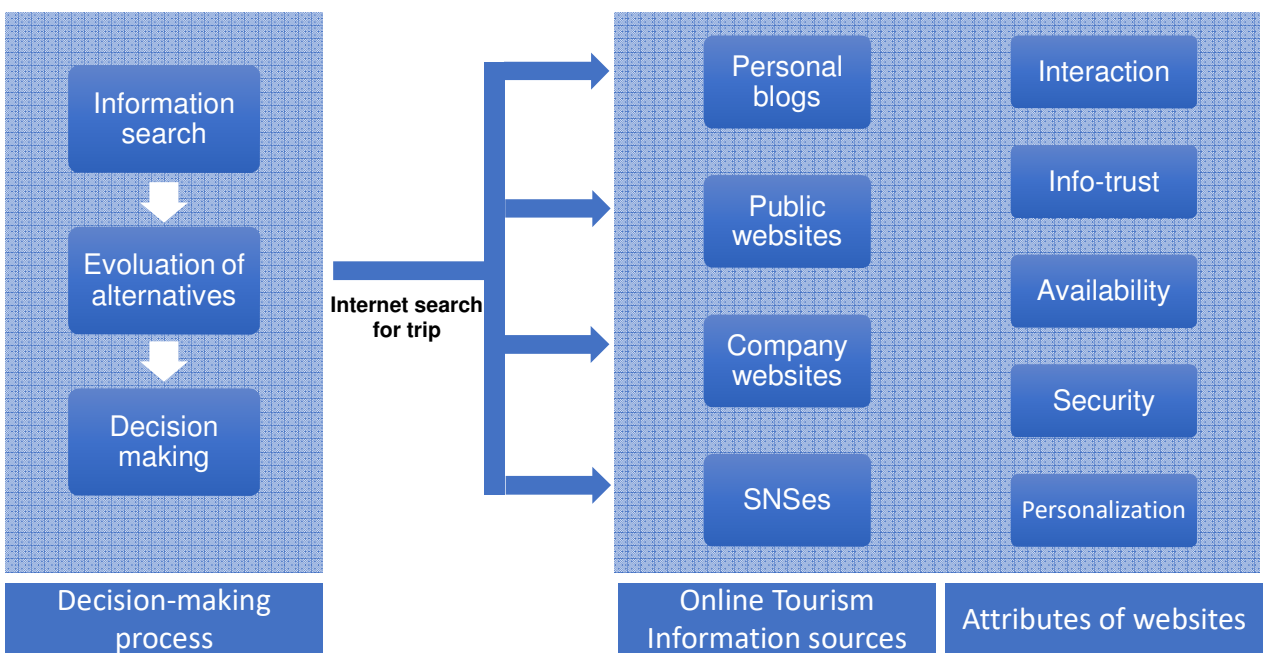

Fig. 1: A conceptual model of the research (adapted from Kim, 2006)

\section{Model 3-Standardization of the Language, Vilella (2003)}

The table below (table 2) shows the authors, parameters, and dimensions in order to standardize the language used through the studies done. This classification according to studies researched by several authors is to answer the analyses of institutions of websites managed by government agencies, ecommerce, e-tourism and so on. The dimensions and parameters are variable according to the authors that is why there is not a chronological order.

Table 2: Standardization of the language according to the authors, mentioned parameters and their belonging to each dimension proposed by the authors

\begin{tabular}{|l|l|l|}
\hline Author/s & Parameters & Dimensions \\
\hline BARBOSA & Comphrensive/Covers and Purpose & Content \\
\hline & Services & Functionality \\
\hline & Visual and Graphic Planning & Usability \\
\hline & Interface & Usability \\
\hline & Communication/Participation/Feedback & Functionality \\
\hline & Navegation & Usability \\
\hline & Present & Content \\
\hline & Metadata & Content \\
\hline & Acessibility & Usability \\
\hline
\end{tabular}




\begin{tabular}{|c|c|c|}
\hline & Perceptiveness & Content \\
\hline & Authority/Copyright & Content \\
\hline & Objectivity & Content \\
\hline & Customization/Personalization & Functionality \\
\hline \multirow[t]{14}{*}{ ESCHENFELDER } & Comphrensive/Covers and Purpose & Content \\
\hline & Visual and Graphic Planning & Usability \\
\hline & Interface & Usability \\
\hline & Services & Functionality \\
\hline & Communication/Participation/Feedback & Functionality \\
\hline & Navegation & Usability \\
\hline & Present & Content \\
\hline & Metadata & Content \\
\hline & Acessibility & Usability \\
\hline & Perceptiveness & Content \\
\hline & Privacy & Functionality \\
\hline & Links & Usability \\
\hline & Authority/Copyright & Content \\
\hline & Objectivity & Content \\
\hline \multirow[t]{10}{*}{ EVANS } & Comphrensive/Covers and Purpose & Content \\
\hline & Visual and Graphic Planning & Usability \\
\hline & Services & Functionality \\
\hline & Communication/Participation/Feedback & Functionality \\
\hline & Navegation & Usability \\
\hline & Present & Content \\
\hline & Acessibility & Usability \\
\hline & Perceptiveness & Content \\
\hline & Privacy & Functionality \\
\hline & Authority/Copyright & Content \\
\hline \multirow[t]{10}{*}{ SMITH } & Comphrensive/Covers and Purpose & Content \\
\hline & Visual and Graphic Planning & Usability \\
\hline & Services & Functionality \\
\hline & Communication/Participation/Feedback & Functionality \\
\hline & Navegation & Usability \\
\hline & Interface & Usability \\
\hline & Present & Content \\
\hline & Acessibility & Usability \\
\hline & Perceptiveness & Content \\
\hline & Privacy & Functionality \\
\hline
\end{tabular}




\begin{tabular}{|l|l|l|}
\hline & Authority/Copyright & Content \\
\hline & Objectivity & Content \\
\hline & Links & Usability \\
\hline & & \\
\hline HUANG \& CHAO & Comphrensive/Covers and Purpose & Content \\
\hline & Visual and Graphic Planning & Usability \\
\hline & Interface & Usability \\
\hline & Navegation & Usability \\
\hline & Links & Usability \\
\hline & Objectivity & Content \\
\hline & & \\
\hline & Comphrensive/Covers and Purpose & Content \\
\hline & Authority/Copyright & Content \\
\hline & Communication/Participation/Feedback & Functionality \\
\hline & Navegation & Usability \\
\hline & Interface & Usability \\
\hline & Present & Content \\
\hline & Acessibility & Usability \\
\hline & Perceptiveness & Content \\
\hline & Customization/Personalization & Functionality \\
\hline & & \\
\hline
\end{tabular}

Source: Adapted from (Vilella, 2003)

\section{Model 4 - Model of Housing Tourism Websites}

According to Daniel Azevedo (2009), Fig 2 represents in more detail the structure of the model combining business performance attributes (with blue background) with attributes commonly used in a usability and credibility assessment of the website (green background).This model interprets, evaluates, acts as a filter, choosing, highlighting, valuing or devaluing aspects of the target object: the website to be evaluated. It is important to say that the objective of this model proposed by Daniel Azevedo (2009) is to ensure success in websites.

The production of an attitude depends on impact, information, references and tariffs. Everytime customers are getting ease and fast information on Internet by websites. According to the model, a production of an attitude goes to success websites. 


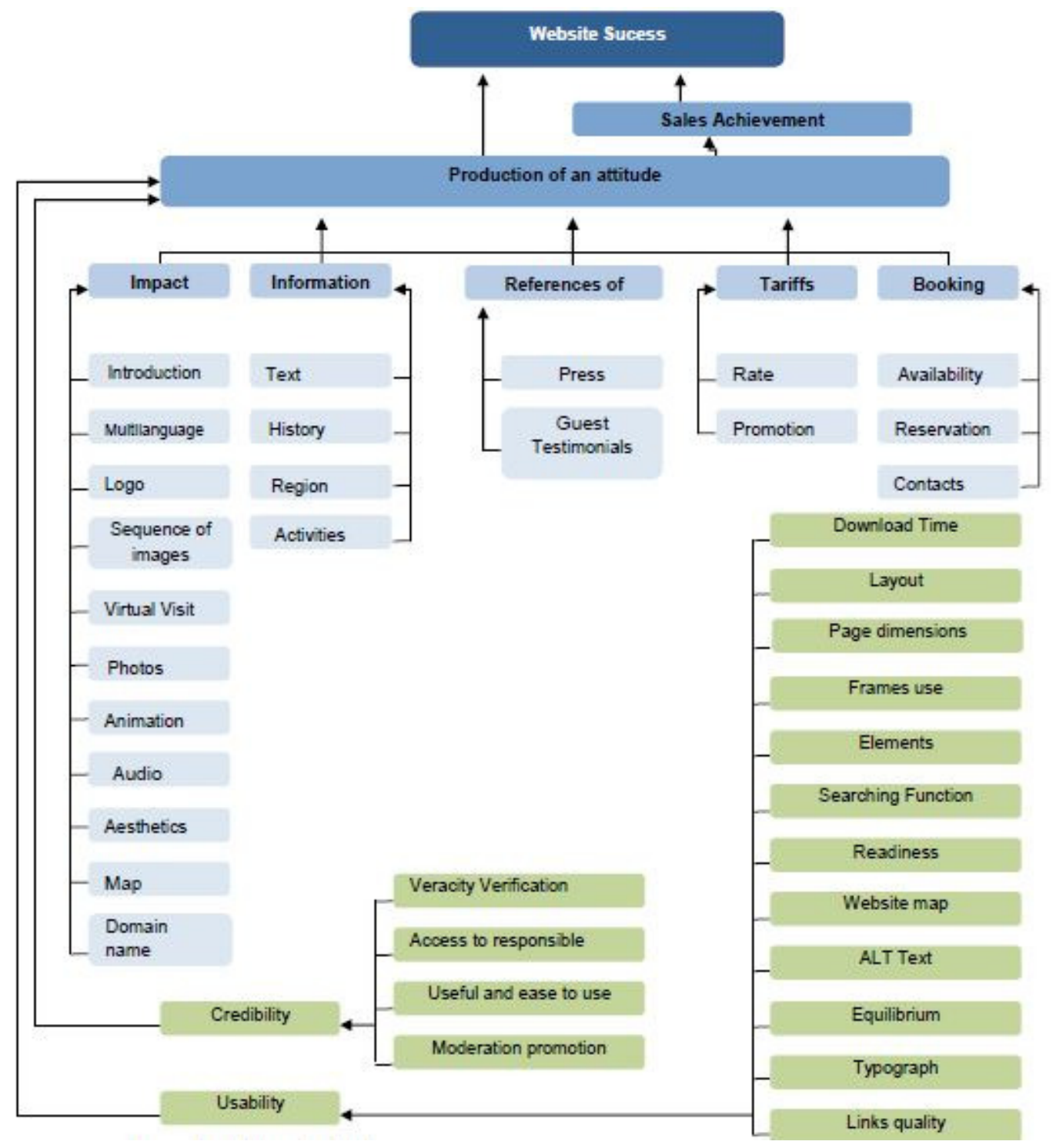

Fig. 2: Model of Housing Tourism Websites (Adapted from Azevedo, 2009)

\section{Model 5-ISO 9126}

ISO/IEC 9126 Software engineering Product quality was an international standard for the evaluation of software quality. It has been replaced by ISO/IEC 25010:2011. The fundamental objective of the ISO/IEC 9126 standard is to address some of the well known human biases that can adversely affect the delivery and perception of a software development project. These biases include changing priorities after the start of a project or not having any clear definitions of "success". By clarifying, then agreeing on the project priorities and subsequently converting abstract priorities (compliance) to measurable values (output data can be validated against schema $\mathrm{X}$ with zero intervention), ISO/IEC 9126 tries to 


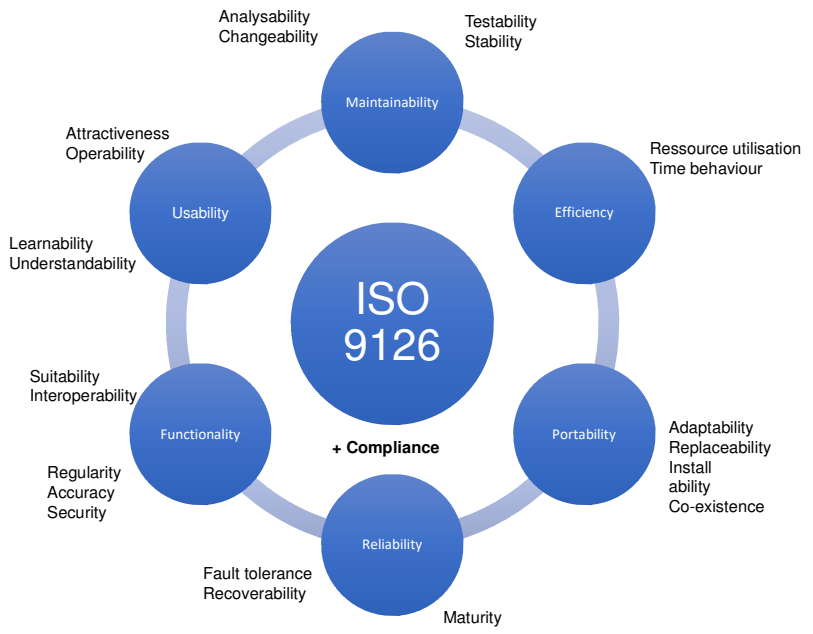

Fig. 3: Model ISO 9126 (adapted from ISO 9126)

Functionality - "A set of attributes that bear on the existence of a set of functions and their specified properties. The functions are those that satisfy stated or implied needs."

Reliability - "A set of attributes that bear on the capability of software to maintain its level of performance under stated conditions for a stated period of time."

Usability - "A set of attributes that bear on the effort needed for use, and on the individual assessment of such use, by a stated or implied set of users."

Efficiency - "A set of attributes that bear on the relationship between the level of performance of the software and the amount of resources used, under stated conditions."

Maintainability - "A set of attributes that bear on the effort needed to make specified modifications."
Portability - "A set of attributes that bear on the ability of software to be transferred from one environment to another."

\section{Proposal of New Model}

These 5 models showed up, in term of parameters to evaluate a website, there are similarities and differences in some of them. It is important to enhance that the first model comprises 12 criteria, second 5 criteria and last by 15 criteria to evaluate a website.

The new model (Fig 4) comes to reinforce the study highlighted parameters of evaluation tourism website believing on quality and also to make sure of its efficiency and efficacy.

According to the previous models, it gives a new picture on how to conduct techniques to evaluate tourism website in tourism destinations presented in Fig 4. 


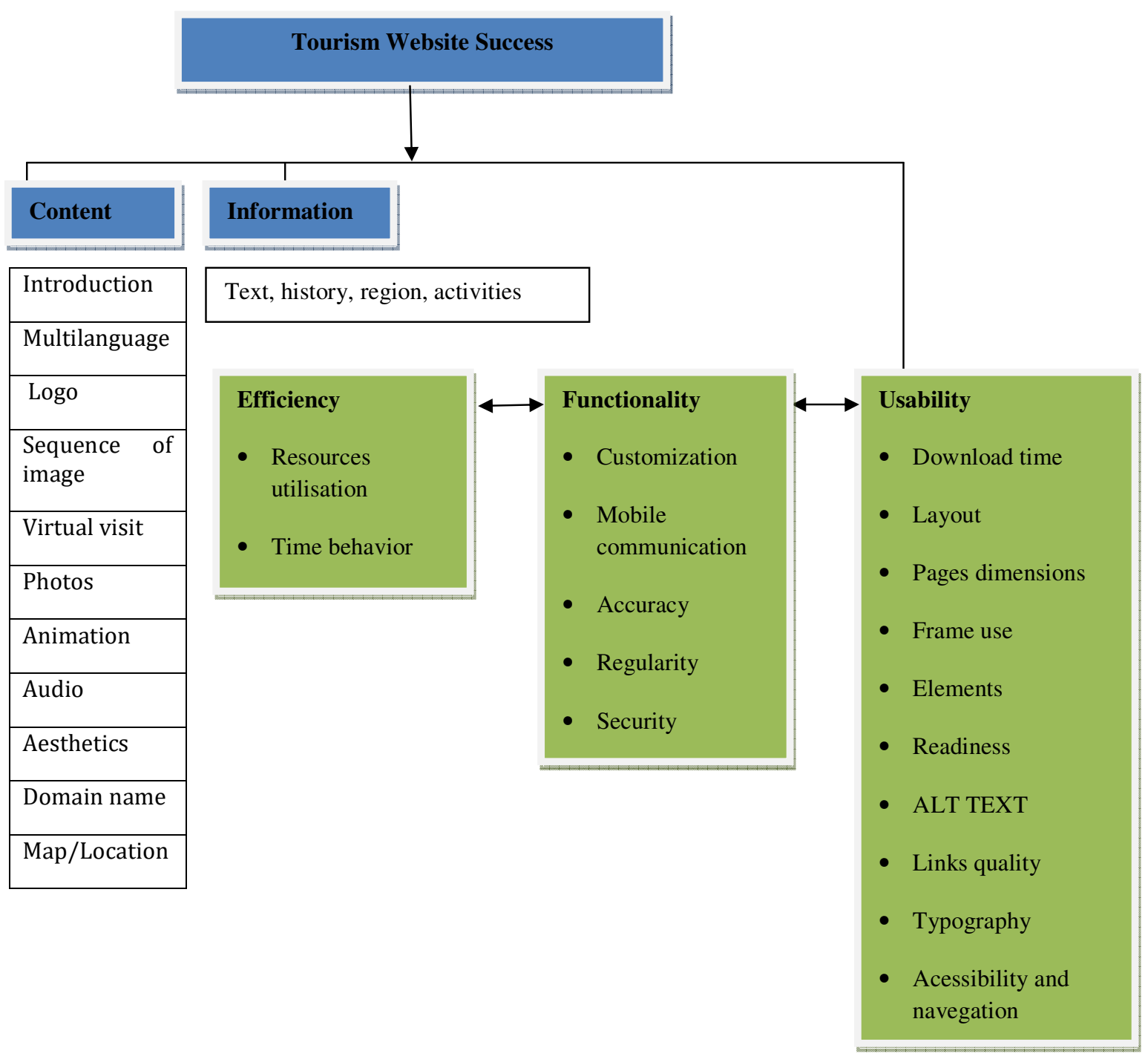

Fig. 4: Model Proposed

\section{Conclusions}

There are various models to evaluate a tourism website.The first model is based on WQI for destination websites assessment system that consists of a set of twelve parameters. The Second model, this study refers to Kim (2006) for the classification of online tourism information sources, so he concluded that there are some elements specifically person blogs, public websites, companies websites, websites for social media.The third model came with many authors who studied parameters, and dimensions, with as the main aim to standardize the language for websites managed by government agencies, ecommerce, e-tourism and so on.The model about evaluation housing tourism websites by Azevedo (2009) showed a new picture in order to guarantee the tourism website success based on usability, credibility, impact, information, tarrifs, reservations and references. The last model proposed by IS09126 is forward quality on websites; each quality sub-characteristic is divided into attributes. An attribute is an entity which can be verified or measured in the 
software product. Attributes are not defined in the standard, as they vary between different software products. These models complement each other. That is why a new model is proposed based on previous studies in their similarieties and differences. Tourism successful business nowadays depends on the new technology, and also is well connected, related to the consumer behaviour to plan a vacation. To reinforce that the new model created is believed to be clear, understandable, and applicable to evaluate a tourism website of a certain destination around the world.

\section{Future Research}

The new model proposed through the similarities and diferences of previous study goes to be applied to a case of tourism analysis website managed by the Government entity-Mozambique in comparison to Portugal tourism website as example.

\section{Acknowledgments}

UNIAG, R\&D unit funded by the FCT Portuguese Foundation for the Development of Science and Technology, Ministry of Science, Technology and Higher Education.

\section{References}

1. Azevedo, D. (2009). Proposal of Home website Evaluation model inTourism.

2. Blain, C. (2005). Destination Branding and Practices from Destination Management Organizations. Travel Research , 43,328-338.

3. Brey, E., So, S., Kim, D., and Morrison, A. (2007). Web-based permission marketing: segmentation for the lodging industry. Tourism Management , 28(6)1408-1416.

4. Cavia, J. F., Rovira, C., Luque, P. D., and Cavaller, V. (2014). Web Quality Index WQI) for official tourist destination websites. Proposal for an assessment system. Tourism Management Perspectives , 9, 5-13.
5. Choi, S. (2007). What does the consumer want from a DMO Website? A study of US and Canadian tourist's Perspectives. Tourism Research , 9,59-72.

6. Chuang, L., and Yuanzhuo, W. (2012). Research on User Behavior Trust in Trustworthy Network. Computer Research and Development.

7. Codina, L., and Marcos, M. C. (2005). Web positioning. Concepts and Tools. The professional of information , 14,84-99.

8. Doolin, B., Burgess, L., and Cooper, J. (2002). Evaluating the use of the Web for tourism marketing: a case study from New Zealand. Tourism Management, 557-561.

9. Garcia, C. (2001). Evaluation of tourism websites. Social Communication .

10.Gretzel, U. (2006). Consumer generated content-trends and implications for tourism and branding. e-review tourism research , 4/3-9-11.

11.Ho, C. L., and Lee, Y. L. (2007). The development of an e-travel service quality scale. Tourism Management , 28(6), 14341449.

12.Huang, C. Y., Chou, C. J., and Lin, P. C. (2010). Involvement theory in constructing bloggers' intention to purchase. Tourism Management, 31(4) 513-526.

13.Jang, S. (2012). Investigating the routes of communication on destination websites. Travel research , 51, 94-108.

14.Kim, J. H. (2006). The effects of tourism information web site factors on usefulness, web site attitude and behavior.

15.Lamas, C. (2010). Interactive media and its advertising. Measuring audiences. Telos

16.Lee, J. W. (2010). study on the effects of hotel brand blog characteristics on the blog flow.

17.Lee, T. M. (2005). The Impact of perceptions of interactivity on customer 
trust and transactions intentions in mobile commerce. Electronic Commerce Research, 6.

18.Lee, T. (2005). The impact of perceptions of interactivity on customer trust and transactions intentions. Electronic Commerce Research .

19.Loiacono, E., \& Chen, D. (2002). WebQual TM revisited:Predicting the intent to reuse a web site. Americas Conference on Information System.

20.Lopez, M. T., Valarez, K., and Altamirano, V. (2016). Collaborative tourism communication 2.0: promotion advertising and interactivity in government tourism websites in Latin America. Social Communication , 249-271.

21.Morrison, A., and Mill, R. (2003). Measuring customer satisfaction with online travel. Paper presented at the information and communication technologies in tourism.

22.Palmer, A., and McCole, P. (2000). The role of electronic commerce in creating virtual tourism destination marketing organisations. International Journal of Contemporary Hospitality Management .
23.Poyatos, F., Martínez, A., and Martínez, B. (2011). Fernández-Poyatos, M.D., Aguirregoitia-Martínez, A., Boix-Martínez, B. (2011): "Camino de Santiago and Xacobeo 20 The route of Santiago and Xacobeu in the tourist portals of the Autonomous Communities. Social Communication , 67.

24.Purinton, E., and Rosen, D. (2004). Website design: Viewing the web as a cognitive landscape. Business Research, 57, 787-794.

25.Schaupp, C., and Belanger, F. (2005). A conjoint analysis of online consumer satisfaction. Electronic Commerce Research , 6(2), 95-111.

26.Unwto. (2010). Annual Report on Definition of Tourism Highlights.

27.Unwto. (2015). Annual Report on Definition of Tourism Highlights.

28.Vilella, R. M. (2003). Contents,Usability and Functionality,three dimensions to analyse eletronic Government Portal State Web. 